\title{
The Surface Tension of Liquid Iron Containing Nitrogen and Oxygen
}

\author{
ZHU Jun and Kusuhiro MUKAI ${ }^{11}$
}

Graduate Student, Department of Materials Science and Engineering, Faculty of Engineering, Kyushu Institute of Technology, Sensui-cho, Tobata-ku, Kitakyushu, Fukuoka-ken, 804-8550 Japan.

1) Department of Materials Science and Engineering, Faculty of Engineering, Kyushu Institute of Technology, Sensui-cho, Tobata-ku, Kitakyushu, Fukuoka-ken, 804-8550 Japan.

(Received on February 23, 1998; accepted in final form on June 4, 1998)

The surface tension liquid of $\mathrm{Fe}-\mathrm{N}, \mathrm{Fe}-\mathrm{O}$ and $\mathrm{Fe}-\mathrm{N}-\mathrm{O}$ alloys was measured with sessile drop method at $1823 \mathrm{~K}$. The effect of nitrogen, oxygen and coexistent nitrogen and oxygen on the surface tension of liquid iron was investigated. The results show that both nitrogen and oxygen are surface-active elements in the liquid iron. The surface tension of liquid iron decreased with increasing nitrogen and oxygen contents. The surface-active nature of nitrogen decreases with increasing of oxygen content.

The variation of surface tension with the activity of the surface-active elements was obtained as follows:

$$
\begin{aligned}
& \text { Fe-N alloy: } \sigma=1930-267 \ln \left(1+45 a_{\mathrm{N}}\right),[\mathrm{O}]=20-30 \text { mass ppm } \\
& \text { Fe-O alloy: } \sigma=1990-318 \ln \left(1+130 a_{\mathrm{O}}\right), P_{\mathrm{N}_{2}}=3.1 \times 10^{-5} \mathrm{~atm} \\
& \text { Fe-O-N alloy: } \sigma=1990-318 \ln \left(1+130 a_{\mathrm{O}}\right)-\left(282-7636 a_{\mathrm{O}}-83152 a_{\mathrm{O}}^{2}\right) \ln \left(1+45 a_{\mathrm{N}}\right)
\end{aligned}
$$

KEY WORDS: surface tension; liquid iron; nitrogen; oxygen; sessile drop.

\section{Introduction}

Several investigators ${ }^{1-3}$ ) have pointed out that Marangoni convection, induced by either a surface or an interfacial tension gradient, may promote mass transfer across the surface/interface and thereby enhances the rate of reactions. Recently, the authors ${ }^{4,5)}$ found that the Marangoni convection occurred on the free surface of liquid iron in the process of nitrogen absorption and desorption in the liquid iron. The Marangoni convection was caused by surface tension gradient due to the difference in nitrogen concentration, because nitrogen is a surface-active element in the liquid iron. The flow velocity of liquid iron due to Marangoni convection affected the rate of nitrogen-molten iron reaction. It is well known that both nitrogen and oxygen are surfaceactive elements in the liquid iron, however, nitrogen is a mildly surface active species compared with oxygen and sulfur. In our previous study, it was found that both surface velocity of liquid iron due to Marangoni convection and the rate of the nitrogen-molten iron reaction decreased with increasing oxygen content.

In order to understand the influence of the Marangoni convection due to nitrogen concentration gradient on the rate of nitrogen-molten iron reaction with various oxygen contents, it is necessary to use the accurate surface tension of $\mathrm{Fe}-\mathrm{N}$ and $\mathrm{Fe}-\mathrm{N}-\mathrm{O}$ alloys to analyze the experimental results and the interaction between oxygen and nitrogen. However, few values of surface tension for $\mathrm{Fe}-\mathrm{N}$ alloy are reported and there is a large difference among different researchers ${ }^{6,7)}$ that might be caused by the presence of surface-active impurities such as $\mathrm{O}$ or $\mathrm{S}$ in the alloy samples or by inappropriate experimental technique. In addition, although the real system of steel is near to Fe-N-O alloy, there is no data available on the surface tension of the Fe-N-O alloy. Therefore, it has hindered the examination of the influence of oxygen on the nitrogen-molten iron reaction rate deeply.

In the present study, the surface tension of $\mathrm{Fe}-\mathrm{N}$ and $\mathrm{Fe}-\mathrm{N}-\mathrm{O}$ alloys were determined experimentally by sessile drop technique. The interaction between nitrogen and oxygen in liquid iron was also discussed.

\section{Experimental Procedure}

\subsection{Apparatus}

Figure 1 shows the experimental apparatus, which consisted of a $\mathrm{LaCrO}_{3}$ heating element furnace and a photographic system. In order to maintain air-tightness of the reaction chamber, a double tube structure was adopted in the study. The reaction tubes were made of high purity alumina $\left(99.8 \% \mathrm{Al}_{2} \mathrm{O}_{3}\right)$. The outer tube is $50 \mathrm{~mm}$ in external diameter, $42 \mathrm{~mm}$ in internal diameter and $700 \mathrm{~mm}$ in length, and the inner tube is $37 \mathrm{~mm}$ in external diameter, $30 \mathrm{~mm}$ in internal diameter and $800 \mathrm{~mm}$ in length. Both ends of the reaction tube are sealed by water-cooled stainless caps. The temperature was measured with a $20: 40 \mathrm{Pt}-\mathrm{Rh}$ thermocouple, which was set directly under the alumina substrate. The maximum temperature for the furnace is $1923 \mathrm{~K}$, and the experimental temperature was $1823 \mathrm{~K}$. The temperature was controlled by a PID digital program controller. 


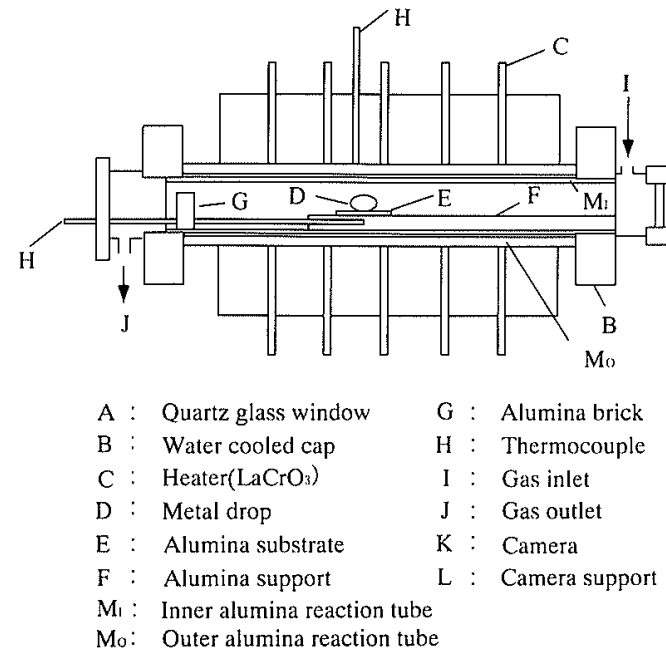

Fig. 1. Schematic diagram of experimental apparatus.

The argon gas was passed through an Ar gas purifier and further deoxidized by $\mathrm{Mg}$ chips heated at $823 \mathrm{~K}$. The nitrogen gas was passed through the columns of $\mathrm{NaOH}$ and $\mathrm{P}_{2} \mathrm{O}_{5}$ to remove $\mathrm{CO}_{2}$ and moisture and then was further deoxidized by two copper nets heated at $873 \mathrm{~K}$. The purified gases were then introduced into the reaction chamber as required.

The droplet shape was taken using a camera connected with a telephotographic lens by a bellows. As the focal distance must be constant in all the experiments to fix the magnification of the photographed image, the focal distance was present in the position of infinity and the focus was adjusted by changing the distance between the molten droplet and the camera fixed on a mechanical table. The table can be moved three dimensionally.

\subsection{Procedure}

High purity electrolytic iron was employed as the base metal for all composition of materials prepared. The composition of the electrolytic iron is shown in Table 1. The iron containing lower oxygen content was prepared by deoxidizing the electrolytic iron in an atmosphere of Ar- $-\mathrm{H}_{2}$ mixture at $1773 \mathrm{~K}$ for two hours, which reduces the oxygen content to 10-20 mass ppm. The $\mathrm{Fe}-\mathrm{O}$ alloys used in the experiment were made by melting the electrolytic iron in an $\mathrm{Al}_{2} \mathrm{O}_{3}$ (99.5\% purity) crucible with high purity $\mathrm{Fe}_{2} \mathrm{O}_{3}(99 \%$ purity)using a vacuum induction furnace. The initial oxygen contents of the specimen were $10-20,250$ and 550 mass ppm. After the experiments, the oxygen contents were 20-30 massppm, 200-250 and 450-500 mass ppm, respectively. The alloys were cut into cylindrical pieces, each weighing about $3 \mathrm{~g}$. The alloy pieces were polished with sandpaper to remove any surface oxide and cleaned with acetone using an ultra sonic automatic washer. The high purity $\mathrm{Al}_{2} \mathrm{O}_{3}(99.8 \%)$ plate $(25.7 \times 25.7 \times 2.5 \mathrm{~mm})$ was used as a substrate in the study. The surface of $\mathrm{Al}_{2} \mathrm{O}_{3}$ plate was washed with ethanol, dried and used without touching the surfaces, in order to avoid any possible contamination.

As shown in Fig. 1 the metal sample was set on the upper surface of an $\mathrm{Al}_{2} \mathrm{O}_{3}$ substrate, and the horizon of the substrate was adjusted by two water levels. After the sample was placed into the furnace, the system was sealed
Table 1. Composition of electrolytic iron. (mass ppm)

\begin{tabular}{ccccccccc}
\hline Element & $\mathrm{C}$ & $\mathrm{S}$ & $\mathrm{P}$ & $\mathrm{Si}$ & $\mathrm{Mn}$ & $\mathrm{Cu}$ & $\mathrm{N}$ & $\mathrm{O}$ \\
\hline Composition & 12 & $<5$ & $<10$ & $<5$ & $<1$ & 1 & 2.5 & 80 \\
\hline
\end{tabular}

and evacuated by a vacuum pump. Then, introduction of argon gas into the reaction chamber and evacuated was repeated three times. After that, the system was heated to experimental temperature in an argon gas atmosphere for $\mathrm{Fe}-\mathrm{O}$ alloys or in an $\mathrm{Ar}-\mathrm{H}_{2}(2: 1)$ gas-mixing atmosphere for liquid iron containing lower oxygen content.

The nitrogen concentration in the liquid iron was determined from the nitrogen partial pressure in the reaction chamber. According to Sievert's law

$$
\begin{aligned}
& 1 / 2 \mathrm{~N}_{2}=\underline{\mathrm{N}} \\
& {[\% \mathrm{~N}] \approx a_{\mathrm{N}}=K \sqrt{P_{\mathrm{N}_{2}}}}
\end{aligned}
$$

where $[\% \mathrm{~N}]$ is nitrogen concentration in the liquid iron, mass $\%, a_{\mathrm{N}}$ is nitrogen activity ( $w_{\mathrm{N}}=1$ mass $\%$ as standard state), $K$ is the equilibrium constant, and $\log K=$ $-518 / T-1.063 .^{8)}$

The total flow rate of gases was maintained at $300 \mathrm{~m} / / \mathrm{min}$ and the total pressure was held constant at $1 \mathrm{~atm}$ in all the experiments. Measurements were made with the following nitrogen partial pressures: $0.33,0.67$ and $1.0 \mathrm{~atm}$. For the $\mathrm{Fe}-\mathrm{O}$ alloy, the nitrogen partial pressure was calculated to be lower than $3.1 \times 10^{-5} \mathrm{~atm}$ from the nitrogen concentration in the electrolytic iron. After the specimen was melted, the droplet was kept in the $\mathrm{Ar}$ or $\mathrm{Ar}-\mathrm{H}_{2}$ atmosphere for $6 \mathrm{~min}$. Then the nitrogen gas with different partial pressure was introduced into the reaction chamber. The $\mathrm{Fe}-\mathrm{N}$ alloys were studied in the atmosphere of $\mathrm{N}_{2}-\mathrm{Ar}-\mathrm{H}_{2}$ mixtures, with hydrogen partial pressure $P_{\mathrm{H}_{2}}$ maintained at $0.003 \mathrm{~atm}$, and the surface tension of $\mathrm{Fe}-\mathrm{O}-\mathrm{N}$ alloys were measured in $\mathrm{N}_{2}-\mathrm{Ar}$ atmosphere.

The photographs of the droplet were taken every 3 -min. The measurement time was $90 \mathrm{~min}$ for one experimental run. In order to obtain the values in the equilibrium state, the results measured in the latter $30 \mathrm{~min}$ were adopted. After the experiment, the symmetry of the droplet was examined and the oxygen and nitrogen contents were analyzed by an oxygen and nitrogen determinator of the infrared rays absorption method with an accuracy of \pm 2 mass ppm.

According to Rotenberg's method, ${ }^{9)}$ the surface tension of the alloy was calculated from the image contour of the droplet, which was input into a computer with a digitizer, by determining the curve with best fit between the numerical solution to the classical Laplace's equation and experimentally measured points. The magnification was determined by a picture of a standard steel ball $(10 \mathrm{~mm}$ in diameter) taken with the same camera and in the same focal distance. The average density of liquid iron obtained in this study is $7.07 \pm 0.23 \times 10^{3}$ $\mathrm{kg} / \mathrm{m}^{3}$ at $1823 \mathrm{~K}$ which is in agreement with the literature values of $7.03-7.2 \times 10^{3} \mathrm{~kg} / \mathrm{m}^{3}$ found by other investigators. ${ }^{10-15)}$ The maximum measurement error is $2 \%$ in the process of the calculation. 


\section{Results and Discussion}

\subsection{Surface Tension of $\mathrm{Fe}-\mathrm{N}, \mathrm{Fe}-\mathrm{O}$ Alloys}

Szyszkowski ${ }^{16)}$ derived the first empirical relation to account for the effect of surface-active elements on the surface tension of liquid iron in a binary melt. Belton ${ }^{17)}$ modified this equation and presented it in a more usable form, by combining the Gibbs adsorption isotherm with the Langmuir isotherm:

$$
\sigma=\sigma^{0}-R T \Gamma_{i(1)}^{0} \ln \left(1+K_{i} a_{i}\right)
$$

where $\sigma^{0}$ is the surface tension of pure iron, $K_{i}$ is the adsorption coefficient of species $i, \Gamma_{i(1)}^{0}$ is the saturated surface excess concentration of the surface active species $i$ at the Gibbs dividing surface of $\Gamma_{1}=0$ and $a_{i}$ is the activity of species $i$ in solution.

$\Gamma_{i(1)}^{0}$ can be determined by calculating the slope of the surface tension to the logarithm of the solute activity curve at high activities of solute according to the Gibbs adsorption equation.

$$
\Gamma_{i(1)}=-\frac{d \sigma}{R T d \ln a_{i}}
$$

where $\Gamma_{i(1)}$ is surface excess concentration, $\mathrm{mol} / \mathrm{cm}^{2}, \sigma$ is surface tension of liquid iron, $\mathrm{mN} / \mathrm{m}$.

Given the value of surface tension, the adsorption coefficient $K_{i}$ can be determined by fitting the experimental data to Eq. (1) with the square least method.

If the surface active element adsorption is assumed to be monolayer, it is also possible to estimate the area $A_{i}$ occupied by each adsorbed unit on the surface from the following relation:

$$
A_{i}=\frac{1}{\Gamma_{i(1)}^{0} \bar{N}}
$$

where $\bar{N}$ is Avogadro's number.

\subsubsection{Effect of Nitrogen on the Surface Tension of Liquid Iron}

The measurements of $\mathrm{Fe}-\mathrm{N}$ alloy surface tension were carried out using pure iron in which the oxygen content was less than 20 mass ppm and the sulfur content was less than 5 mass ppm. The variation of the surface tension of Fe-N alloys at $1823 \mathrm{~K}$ is plotted in Fig. 2. The results indicated a reduction in the surface tension of liquid iron with increasing nitrogen concentration. The surface tension of liquid iron was found to decrease by about $300 \mathrm{mN} / \mathrm{m}$ over the $P_{\mathrm{N}_{2}}$ range of $3.1 \times 10^{-5}$ to $1.0 \mathrm{~atm}$. The results obtained by Kozakevitch, ${ }^{12,14)}$ Halden $^{13)}$ and Ershov ${ }^{15)}$ with sessile drop method are also shown in Fig. 2. It can be seen that the slope of the variation of surface tension of liquid iron with nitrogen in this study is close to the result of Ershov ${ }^{15}$ and is steeper than that of other researchers. Ershov ${ }^{15}$ determined the depression in the surface tension of liquid iron in the same range of nitrogen partial pressure to be about $290 \mathrm{mN} / \mathrm{m}$. The result obtained by Halden ${ }^{13)}$ is $200 \mathrm{mN} / \mathrm{m}$. However, the contents of oxygen and sulfur in the materials were about 70 and 50 mass ppm, respectively. This reveals that since the stronger surface-active elements such as oxygen and sulfur in the liquid were controlled at a lower content in

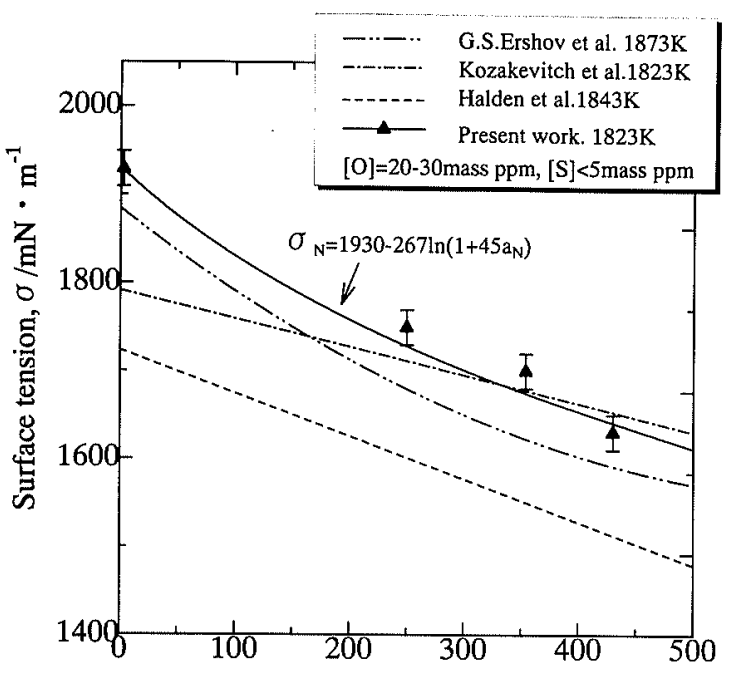

Nitrogen concentration, $\mathrm{w}_{\mathrm{N}} /$ mass $\mathrm{ppm}$

Fig. 2. Variation of surface tension of liquid iron with nitrogen concentration.

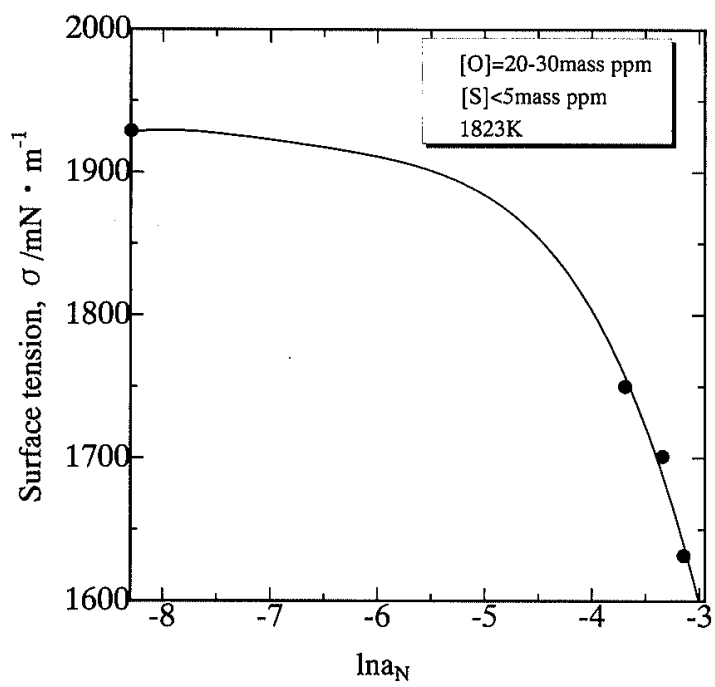

Fig. 3. Relation between surface tension of liquid and activity of nitrogen.

the present study, the surface tension gradient was steeper due to the surface tension of pure iron being higher and the effect of nitrogen on the surface tension became more sensitive.

Figure 3 is a plot of the surface tension of the $\mathrm{Fe}-\mathrm{N}$ alloy as a function of $\ln a_{\mathrm{N}}, a_{\mathrm{N}}$ is nitrogen activity relative to 1 mass $\%$ solution in molten iron. The surface excess concentration of nitrogen at saturation was found to be $17.8 \times 10^{-10} \mathrm{~mol} / \mathrm{cm}^{-2}$. The effect of oxygen was ignored because the oxygen content was very low in this situation. The value of $K_{\mathrm{N}}$ was determined to be 45 , and the variation of the surface tension of liquid iron with nitrogen activity can be written as

$$
\sigma=1930-267 \ln \left(1+45 a_{\mathrm{N}}\right) \quad \mathrm{mN} / \mathrm{m}
$$

The surface tension variation predicted with Eq. (5) is plotted in Fig. 2.

\subsubsection{Effect of Oxygen on the Surface Tension of} Liquid Iron

It is well known that oxygen is a stronger surface-active 


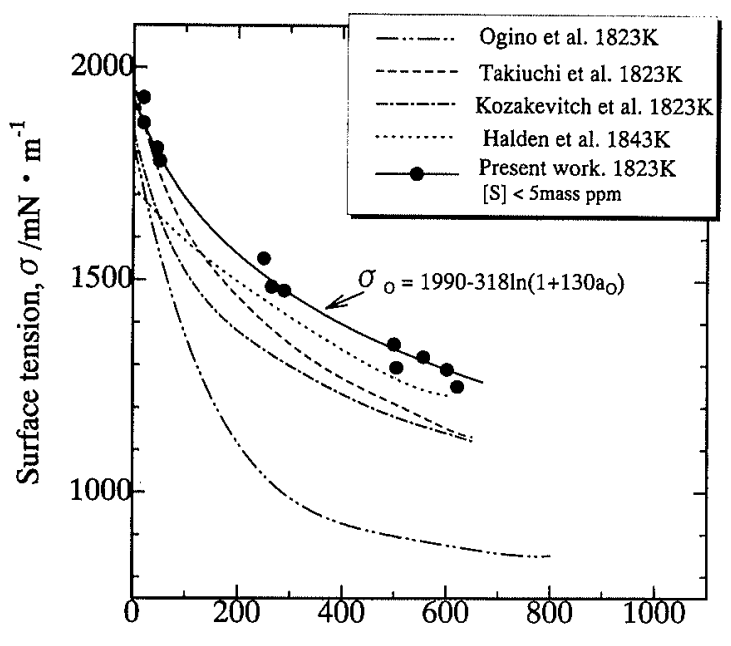

Oxygen concentration, $\mathrm{w}_{\mathrm{O}}$ /mass ppm

Fig. 4. Variation of surface tension of liquid iron with oxygen concentration.

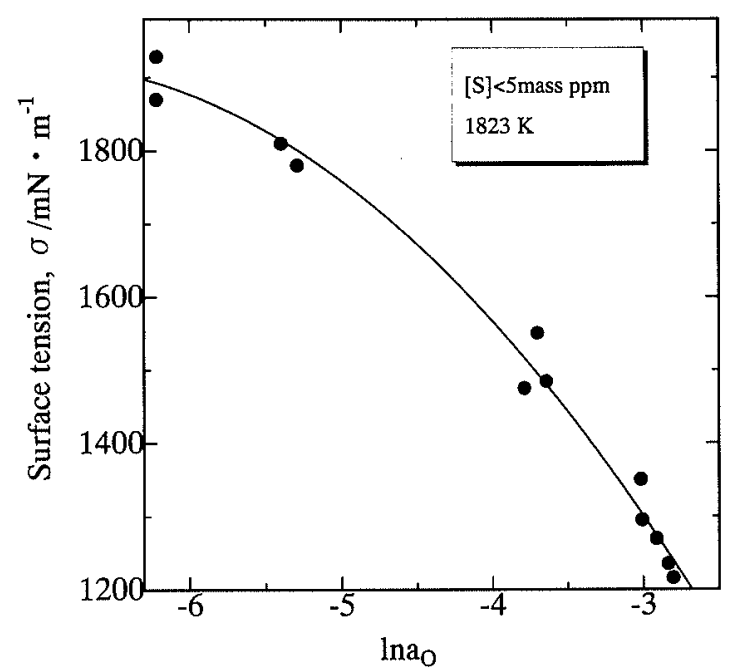

Fig. 5. Relation between surface tension of liquid and activity of oxygen at $1823 \mathrm{~K}$

element and the surface tension of liquid iron at constant temperature decreases with increasing oxygen contents. Figure $\mathbf{4}$ shows the effect of oxygen on the surface tension of liquid iron measured in the present and previous studies. ${ }^{10-13)}$ However, a discrepancy exists among the values reported by different investigators. The values obtained in the present study are relatively bigger than that of others, which can be attributed to relatively lower impurities such as sulfur in the iron and a good airtightness of the reaction chamber. The content of sulfur is less than 5 mass ppm in the present study, however, it was 50,34 and 10 massppm for the experiments by Halden, ${ }^{13)}$ Takiuchi ${ }^{11)}$ and Ogino, ${ }^{10)}$ respectively.

Figure 5 shows the relation between surface tension and $\ln a_{\mathrm{O}}$ in this study. $a_{\mathrm{O}}$ is oxygen activity relative to 1 mass\% solution in molten iron. The surface excess concentration of oxygen at saturation is $2.12 \times 10^{-9}$ $\mathrm{mol} / \mathrm{cm}^{2}$, with the average area occupied by one oxygen ion, $A_{\mathrm{O}}$, is $7.81 \times 10^{-16} \mathrm{~cm}^{2}$, which lies in the range $7.62 \times 10^{-16}-9.2 \times 10^{-16}$ measured by many investigators. ${ }^{13,19,20)}$ The effect of oxygen on the surface of liquid iron can be expressed using the following equation based

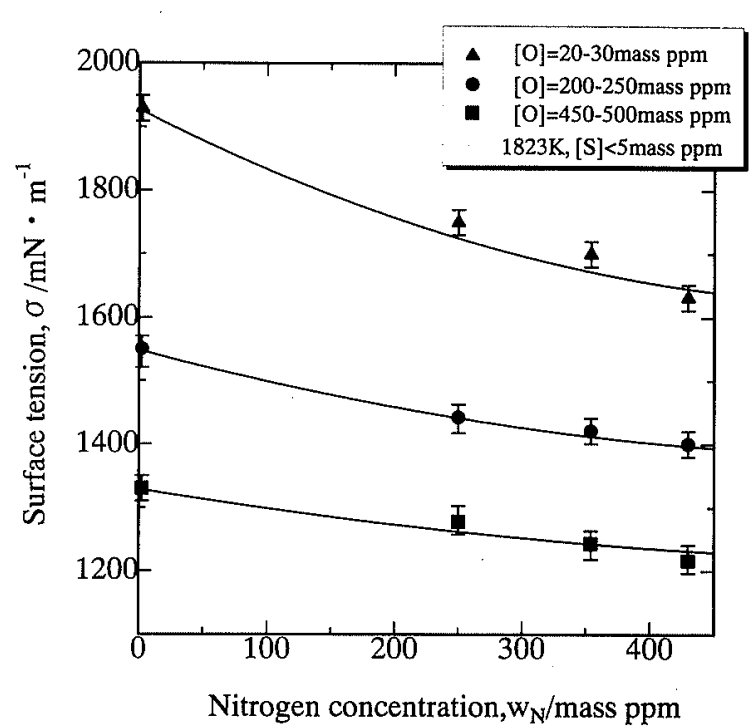

Fig. 6. Relation between surface tension of liquid and nitrogen concentration with various oxygen contents.

on the Belton's ${ }^{17)}$ model:

$$
\sigma=1990-318 \ln \left(1+130 a_{\mathrm{o}}\right)
$$

The surface tension variation predicted using Eq. (6) is plotted in Fig. 4. As Eq. (5) describes the change of surface tension of $\mathrm{Fe}-\mathrm{N}$ alloy with nitrogen activities, the surface tension of pure iron $\sigma_{\mathrm{N}}^{0}$ represents the surface tension that nitrogen activity equals 0 , but about 20 mass ppm oxygen content still exists. However, the $\sigma_{\mathrm{O}}^{0}$ of Eq. (6) is determined when oxygen activity equals 0 and $a_{\mathrm{N}}<0.00025$. Thus, the $\sigma_{\mathrm{O}}^{0}$ should be larger than $\sigma_{\mathrm{N}}^{0}$.

\subsection{Surface Tension of $\mathbf{F e}-\mathbf{N}-\mathrm{O}$ Alloys}

The surface tension of $\mathrm{Fe}-\mathrm{N}-\mathrm{O}$ was measured under the condition of coexistence of the surface-active elements, nitrogen and oxygen. The experiments were performed on $\mathrm{Fe}-\mathrm{O}$ alloys containing 250 and 550 mass ppm initial oxygen contents, and various nitrogen concentrations were controlled by adjusting nitrogen partial pressure: $3.1 \times 10^{-5}, 0.33,0.67$ and $1.0 \mathrm{~atm}$. Figure 6 shows the change of surface tension of liquid iron containing various oxygen contents as a function of nitrogen concentration. The results of the $\mathrm{Fe}-\mathrm{N}$ alloy, which contained about 20-30 mass ppm oxygen, are also plotted in Fig. 6. The curves were plotted with Eqs. (5) and (15). It can be seen that the surface tensions of liquid iron decrease with increasing the nitrogen concentration whether the oxygen content is low or high. However, the decreasing rate of the surface tension with increasing nitrogen concentration becomes smaller as oxygen content increases in the liquid iron. When oxygen content is altered from $20-30$ to $450-500$ mass ppm, the depression in the surface tension of liquid iron changes from 300 to $110 \mathrm{mN} / \mathrm{m}$ in the range of nitrogen partial pressure: $3.1 \times 10^{-5}$ to $1.0 \mathrm{~atm}$. This indicates that the surface-active degree of nitrogen decreases with the increasing of oxygen content.

As multiple surface-active elements coexist in the liquid iron, the interaction between the oxygen and nitrogen should be considered in the analysis of the experimental 


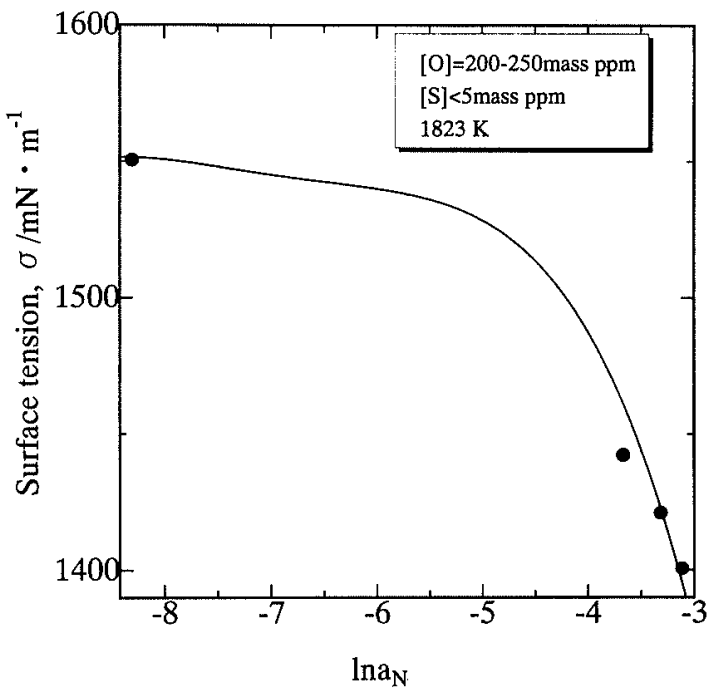

Fig. 7. Relation between surface tension of liquid and activity of nitrogen.

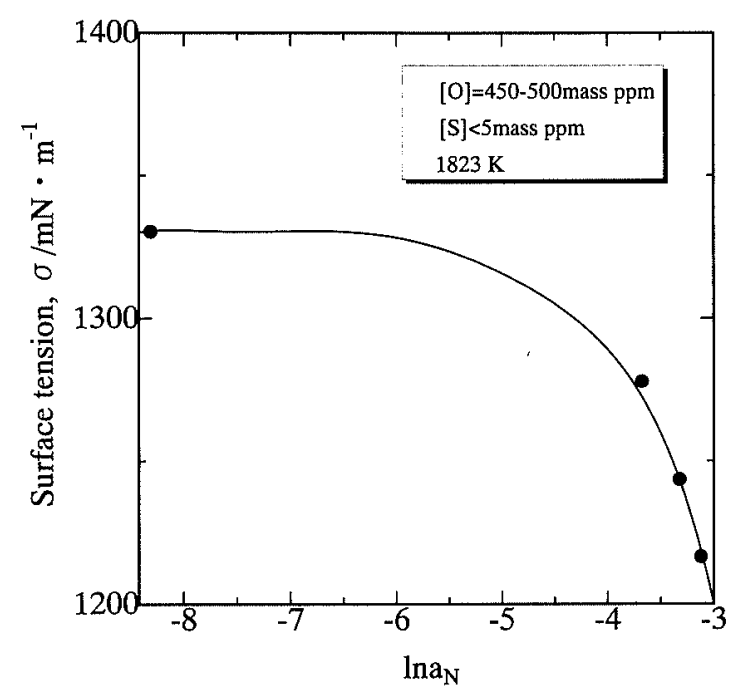

Fig. 8. Relation between surface tension of liquid and activity of nitrogen.

results. The activity coefficients of nitrogen and oxygen is calculated by the following equations:

$$
\begin{aligned}
& \log f_{\mathrm{O}}=e_{\mathrm{O}}^{\mathrm{O}}[\% \mathrm{O}]+e_{\mathrm{O}}^{\mathrm{N}}[\% \mathrm{~N}] \\
& \log f_{\mathrm{N}}=e_{\mathrm{N}}^{\mathrm{O}}[\% \mathrm{O}]+e_{\mathrm{N}}^{\mathrm{N}}[\% \mathrm{~N}]
\end{aligned}
$$

where $f_{i}$ is activity coefficient of species $i$ in liquid iron, refereed to a 1 mass $\%$ standard states for dissolved specie $i$ is in pure iron. $e_{i}^{j}$ is interaction parameter. The values of the interaction coefficients for oxygen and nitrogen are

$$
e_{\mathrm{O}}^{\mathrm{O}}=-0.17{ }^{8)} e_{\mathrm{N}}^{\mathrm{O}}=-0.12,{ }^{8)} e_{\mathrm{O}}^{\mathrm{N}}=-0.14,{ }^{8)} \text { and } e_{\mathrm{N}}^{\mathrm{N}}=0 .{ }^{8)}
$$

The variations of surface tension of liquid iron with nitrogen activity are plotted in Figs. 7, 8 with different oxygen contents. The slope of the curve in Fig. 7 increases rapidly until it reaches a maximum value in the range of high nitrogen partial pressure $(0.67-1.0 \mathrm{~atm})$. Thus, the surface excess concentration of nitrogen calculated from the maximum value of slope can be regarded as the saturated surface excess concentration of nitrogen for the liquid iron containing 200-250 massppm oxygen under this condition. The same result is also obtained in
Table 2. Surface excess concentration of nitrogen at saturation with various oxygen contents.

\begin{tabular}{lccc}
\hline [O], mass ppm & $20-30$ & $200-250$ & $450-500$ \\
\hline$\Gamma_{\mathrm{N}(\mathrm{Fe})}^{0}, \mathrm{~mol} / \mathrm{cm}^{2}$ & $17.8 \times 10^{-10}$ & $9.56 \times 10^{-10}$ & $7.21 \times 10^{-10}$ \\
\hline
\end{tabular}

Fig. 8 for alloy of $450-500$ mass ppm oxygen contents. The surface excess concentration of nitrogen at saturation with various oxygen contents is shown in Table 2 . It can be seen that the surface excess concentration of the nitrogen at saturation decreases with the increasing of oxygen contents.

As the nitrogen and oxygen are coadsorption on the surface of liquid, it is useful to determine the relation between the surface tension and activity of oxygen and nitrogen. Studies on the surface tensions of ternary system have been carried out by Ogino et al. ${ }^{22)}$ The surface tension of $\mathrm{Fe}-\mathrm{O}-\mathrm{S}$ alloy was described with Eq. (9), which was derived from Eq. (2) under the assumption of ideal additivity of $\mathrm{Fe}-\mathrm{O}$ and $\mathrm{Fe}-\mathrm{N}$ system.

$$
\sigma=\sigma^{0}-R T \Gamma_{2}^{0} \ln \left(1+K_{2} a_{2}\right)-R T \Gamma_{3}^{0} \ln \left(1+K_{3} a_{3}\right)
$$

where subscript 2, 3 represent the two surface active components in liquid iron. If the Eq. (9) is applied in $\mathrm{Fe}-\mathrm{N}-\mathrm{O}$ alloys of the present study, then

$$
\sigma=\sigma^{0}-R T \Gamma_{\mathrm{O}}^{0} \ln \left(1+K_{\mathrm{O}} a_{\mathrm{O}}\right)-R T \Gamma_{\mathrm{N}}^{0} \ln \left(1+K_{\mathrm{N}} a_{\mathrm{N}}\right)
$$

As the nitrogen concentration was very low in the $\mathrm{Fe}-$ $\mathrm{O}$ alloy, the $\sigma^{0}$ deduced from $\mathrm{Fe}-\mathrm{O}$ alloy was adopted. Thus,

$$
\sigma=1990-318 \ln \left(1+130 a_{\mathrm{O}}\right)-267 \ln \left(1+45 a_{\mathrm{N}}\right) \ldots
$$

Ogino $e t a l .{ }^{22)}$ concluded from a simplified analysis that the data was consistent with ideal competitive adsorption of the two solutes, i.e., the Langmuir isotherm constant from the binary systems were applicable to the ternary system. This is, however, a rough first approximation. The interaction of nitrogen and oxygen could not be explained with this relation.

The Gibbs adsorption isotherm of $\mathrm{Fe}-\mathrm{N}-\mathrm{O}$ alloy at the dividing surface of $\Gamma_{\mathrm{Fe}}=0$, is given as

$$
d \sigma=-\Gamma_{\mathrm{N}(\mathrm{Fe})} d \mu_{\mathrm{N}}-\Gamma_{\mathrm{O}(\mathrm{Fe})} d \mu_{\mathrm{O}}
$$

Integration of Eq. (12) from $a_{\mathrm{O}}=0$ to $a_{\mathrm{O}}$ and $a_{\mathrm{N}}=0$ to $a_{\mathrm{N}}$, gives

$$
\sigma=\sigma^{0}-R T \Gamma_{\mathrm{O}(\mathrm{Fe})}^{0} \ln \left(1+K_{\mathrm{O}} a_{\mathrm{O}}\right)-R T \Gamma_{\mathrm{N}(\mathrm{Fe})}^{0 \prime} \ln \left(1+K_{\mathrm{N}} a_{\mathrm{N}}\right)
$$

where $\Gamma_{\mathrm{N}(\mathrm{Fe})}^{0 \prime}$ is the saturated surface species concentration of nitrogen at the oxygen activity $a_{\mathrm{O}} \cdot \Gamma_{\mathrm{N}(\mathrm{Fe})}^{0 \prime}$ decreases with the increasing of oxygen concentration as shown in Table 2. With the values of $\Gamma_{\mathrm{N}(\mathrm{Fe})}^{0 \prime}$ in Table 2, the following relation was obtained using the least square method.

$$
R T \Gamma_{\mathrm{N}}^{0}=282-7636 a_{\mathrm{O}}+83152 a_{\mathrm{O}}^{2}
$$

If the Eq. (14) is substituted into Eq. (13), and the $K_{\mathrm{N}}$, $K_{\mathrm{O}}$ obtained from Eqs. (5), (6) are adopted, then

$$
\begin{aligned}
\sigma= & 1990-318 \ln \left(1+130 a_{\mathrm{O}}\right) \\
& -\left(282-7636 a_{\mathrm{O}}+83152 a_{\mathrm{O}}^{2}\right) \ln \left(1+45 a_{\mathrm{N}}\right)
\end{aligned}
$$




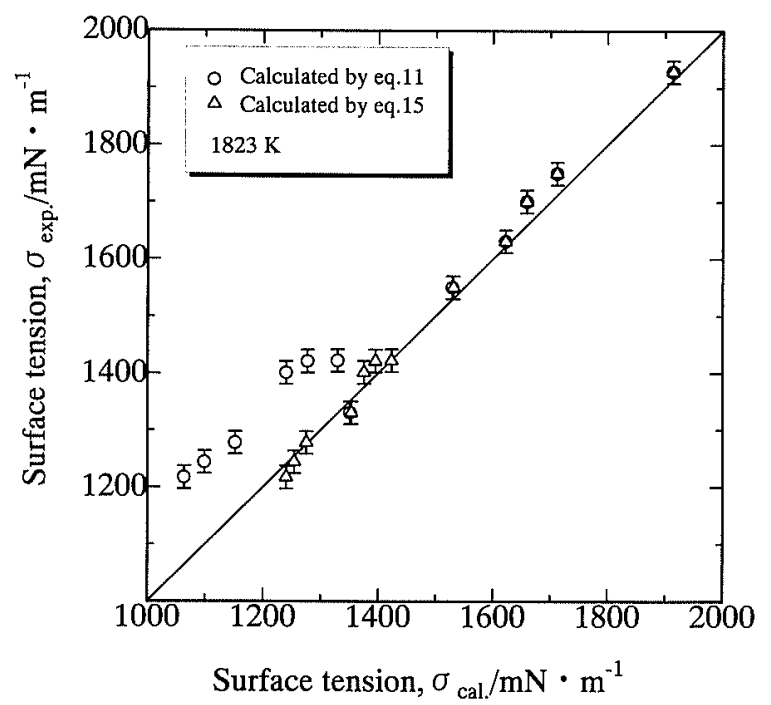

Fig. 9. Comparison of the experimental values with the calculated values of the surface tension of molten $\mathrm{Fe}-\mathrm{N}-\mathrm{O}$ alloy.

The values of surface tension of the experimental measurements and those calculated from Eqs. (11), (15) are all shown in Fig. 9. It can be seen that both values calculated from Eqs. (11), (15) are the same or similar to the experimental results when the oxygen and nitrogen contents are low. However, as the oxygen content increases, the values calculated from Eq. (15) appears closer to the experimental results than the one obtained from Eq. (11). It reveals that the interaction between the nitrogen and oxygen would affect the surface tension of liquid iron and the dependence of surface tension of liquid iron on the nitrogen and oxygen can be described using Eq. (15) effectively in the present study. The predicted surface tension variations are also plotted in Fig. 6 using Eq. (15) with various oxygen contents. As the Eq. (15) is derived from the Gibbs adsorption isotherm of ternary system, it could be deduced that the equation might be applied to other ternary system. Practically, there are more than two surface-active species coexistence in real systems of steel, such as oxygen, sulfur, nitrogen $e t c$. It is necessary to establish a relation between the surface tension and activity of surface-active spices for a multicomponent system in the future study.

\section{Conclusion}

(1) The surface tension of $\mathrm{Fe}-\mathrm{O}, \mathrm{Fe}-\mathrm{N}$ and $\mathrm{Fe}-\mathrm{N}-\mathrm{O}$ alloys was measured with the sessile drop method. The results show that both nitrogen and oxygen are surfaceactive elements, however, nitrogen is a milder surfaceactive element than oxygen.

(2) The surface excess concentration at saturation was derived in the study. Fe--N alloy, $\Gamma_{\mathrm{N}(\mathrm{Fe})}^{\prime \prime}=17.8 \times 10^{-10}$ $\mathrm{mol} / \mathrm{cm}^{2} ; \mathrm{Fe}-\mathrm{O}$ alloy, $\Gamma_{\mathrm{O}(\mathrm{Fc})}^{0}=21.2 \times 10^{-10} \mathrm{~mol} / \mathrm{cm}^{2}$. For $\mathrm{Fe}-\mathrm{N}-\mathrm{O}$ alloy, the surface excess concentration of nitrogen decreases with the increasing oxygen contents.

(3) The variation of surface tension with the activity of surface active element can be written as follows:

1) Fe-N alloy: $\sigma=1930-267 \ln \left(1+45 a_{N}\right)$,

$$
[\mathrm{O}]=20-30 \text { mass ppm }
$$

2) Fe-O alloy: $\sigma=1990-318 \ln \left(1+130 a_{0}\right)$,

$$
P_{\mathrm{N}_{2}}=3.1 \times 10^{-5} \mathrm{~atm}
$$

3) Fe-N-O alloy: $\quad \sigma=1990-318 \ln \left(1+130 a_{0}\right)$

$$
\begin{aligned}
& -\left(282-7636 a_{\mathrm{O}}-83152 a_{\mathrm{O}}^{2}\right) \\
& \times \ln \left(1+45 a_{\mathrm{N}}\right)
\end{aligned}
$$

\section{REFERENCES}

1) K. Mukai: Materia Japan, 34 (I995), 395.

2) P. V. Riboud and L. D. Lucas: Can. Metall. Q., 20 (1981), 199

3) J. Deng and F. Oeters: Steel Res., 61 (1990), 438.

4) Zhu Jun and K. Mukai: ISIJ Int., 38 (1998), 220.

5) Zhu Jun and K. Mukai: ISIJ Int., submitted

6) B. J. Keene: Int. Mater. Rev., 33 (1988), 1.

7) A. Sharan, T. Nagasaka and A. W. Cramb: Metall. Mater. Trans., 25B (1994), 626.

8) Recommendation Equilibrium Values of Metallurgical Reaction: The 19th Committee of Steelmaking, JSPS, (1984), 17.

9) Y. Rotenberg, L. Boruvka and A. W. Neumann: J. Colloid Interface Sci., 93 (1983), 169.

10) K. Ogino, K. Nogi and Y. Koshida: Tetsu-to-Hagané, 59 (1973), 1380.

11) K. Mukai, T. Kato and H. Sakao: Tetsu-to-Hagané, 59 (1973), 55.

12) P. Kozakevich and G. Urbain: Mem. Sci. Rev. Metall., 58 (1961), 517.

13) F. A. Halden and W. D. Kingery: J. Phys. Chem., (1955), 557.

14) P. Kozakevich: Surface Phenomena of Metals' Monograph, London, Society of Chemical Industry, 28 (1968), 223.

15) G. S. Ershov and V. M. Bychev: Russ. Metall, 4 (1975), 45.

16) B. Von Szyszkowski: Z. Phys. Chem., 64 (1908), 385.

17) G. R. Belton: Metall. Trans., 7B (1976), 35.

18) N. Shinozaki, T. Kurashige, K. Mori and Y. Kawai: J. Jpn. Inst. Met., 46 (1982), 60 .

19) A. Kasama, A. McLean, W. A. Miller, Z. Morita and M. J. Ward: Can. Metall. Q., 22 (1983), 9.

20) G. R. Belton: Advanced Physical Chemistry for Process Metallurgy, Academic Press, New York, (1997), 187.

2I) J. W. Gibbs: Collected works, Yale University Press, New Haven, 1 (1948), 219.

22) K. Ogino, K. Nogi and C. Hosoi: Tetsu-to-Hagané, 69 (1983), 1989. 